\title{
The Esterase Isozymes of Tetrahymena: Their Distribution in Isolated Cellular Components and their Behavior during the Growth Cycle'
}

\author{
SALLY LYMAN ALLEN \\ Zoology Department, The University of Michigan \\ Ann Arbor, Michigan
}

In recent years molecular heterogeneity of proteins has often been observed, particularly for enzymes, where the existence of multiple molecular forms has been extensively domumented (Wróblewski, '61). Markert and Møller ('59) introduced the concept of an isozyme, which they defined as one of the "molecular forms in which proteins may exist with the same enzymatic specificity" within a single organism. This term has gained wide popularity and has been used in an operational sense to cover any series of enzymes with roughly similar properties regardless of genetic relationship. In nearly all cases the genetic relationships are not known. However, where the genetic relationships are known, informative distinctions among degrees of relationship can be drawn (Allen, Misch, and Morrison, '63a, '63b). In this paper, I shall use the term isozyme to apply to one of a series of molecular forms of an enzyme controlled by a single gene. Two examples of this type of isozyme are the alkaline phosphatases of Escherichia coli (Bach et al., '61; Levinthal, Signer, and Fetherolf, '62) and certain esterases of variety 1 of Tetrahymena pyriformis (S. L. Allen, '60, '61a).

In $T$. pyriformis the esterase isozymes are resolved by electrophoresis in starch gels (S. L. Allen, '60). There are two groups of isozymes that are discontinuously distributed among the various inbred strains. Each group is controlled by an allele at the $E-1$ locus (S. L. Allen, '61a) and the E-1 locus is linked to the $m t$ (mating type) locus (S. L. Allen, '64). Both groups of isozymes are present in heterozygotes.

Clonal analysis indicated that all the isozymes of a group are present in single cells of each homozygote, and all isozymes of both groups are present in a heterozygous cell before phenotypic drift begins (S. L. Allen, '61a). However, the activity of an isozyme is sensitive to its environment and varies in cells grown under different conditions. The most striking environmental variable was the age of the culture, and changes in the pattern of activities were recorded as a function of the growth cycle (S. L. Allen, '60). A detailed study of these changes is reported in this paper.

Preliminary observations suggested that these isozymes might be localized to different cellular components (S. L. Allen, '61a, '61b). One of the isozymes in each group appeared to be restricted to a small particle fraction, and early experiments suggested that the site of localization might be the cilia. These observations are extended in this report. Using several experimental approaches the distribution of the esterase isozymes was examined in isolated components of cells in the stationary phase. These experiments indicate that the small particles with which one of the isozymes is associated are not the cilia but are the microsomes. This microsomal localization is supported by certain growth cycle data.

These results are discussed with respect to the genetic control of these esterases and their homology between different genotypes. The thesis is developed that the microsomal isozyme may represent the molecular form of the newly synthesized esterase and that the other isozymes may be derived from this form.

' Supported by Research Grant CA-03545 from the National Cancer Institute, Public Health Service, and by Institutional Grant IN-40C to the University of Michigan from the American Cancer Society. 


\section{MATERIALS AND METHODS}

Material. Stock cultures of three inbred strains of variety 1 of $T$. pyriformis served as the source of the experimental material. Strains $A$ and $B$ are $E-1^{B} / E-1^{B}$ and strain $C$ is $E-1^{c} / E-1^{c}$. The origins of these inbred strains and a detailed description of their genotypes may be found elsewhere (S. L. Allen, '60, '64; Nanney, '59).

Growth conditions. Most experiments employed cultures grown in $1 \%$ proteosepeptone $(\mathrm{pH} 7.0)$ at $30^{\circ} \mathrm{C}$ for five days. Higher concentrations of proteose-peptone ( $2 \%$ or $4 \%$ ) were used in some experiments. In the growth cycle experiments cultures were harvested after varying numbers of days. In a few experiments other media were used: Cerophyl rye grass inoculated with Aerobacter aerogenes (designated "bacterized" medium), a skimmed milk medium (Allen, Hegenaur, and Licht, unpublished) or a synthetic medium of known composition (Elliott, Brownell, and Gross, '54).

Harvesting of cells. Cells were collected by low-speed centrifugation and washed by one or more changes of glass distilled water. In most experiments cell concentration was controlled by measuring the volume of cell packs after centrifugation at $200-1,000 \times g$ in a Constable protein tube and then diluting with the appropriate medium to the desired concentration. All whole cell extracts and cell fractions were disrupted by repeated rounds of freeze-thawing before electrophoresis. No changes have been observed in extracts stored in a deep-freeze at $-20^{\circ} \mathrm{C}$ for over three years.

Identification of the E-1 esterases. Extracts were inserted in starch gels and electrophoresis was carried out in the horizontal position for five hours at room temperature $\left(23-26^{\circ} \mathrm{C}\right)$, as previously described (S. L. Allen, '60; Allen, Misch, and Morrison, '63a). Recently boric acidTris (hydroxymethyl) aminomethane buffers of similar molarities were substituted for the boric acid-NaOH buffers previously used. Separations of E-1B were carried out in starch gels of $\mathrm{pH} 8.0$ and of E-1C in gels of $\mathrm{pH} 7.5$ or $\mathrm{pH} 7.8$. The end tray buffer was $\mathrm{pH} 7.5 \mathrm{in}$ all electrophoretic runs. The E-1 esterases were identified by incubating the starch slices for one-half to four hours at room temperature in pans in a reaction mixture containing $0.01 \%$ a-naphthyl propionate (synthesized by Dr. Robert L. Hunter, Department of Anatomy, Medical School, Stanford University), $0.01 \mathrm{M}$ sodium taurocholate (Nutritional Biochemicals Corporation), and $0.1 \%$ Fast Blue RR (4'-amino-2', 5-dimethylbenzanilide, C. I. no. 37155; Carbic-Hoechst Corporation) in $0.1 \mathrm{M}$ Sörensen's phosphate buffer at $\mathrm{pH}$ 7.4.

Differential centrifugation. A variety of schedules was used to separate cell fractions. The most satisfactory was one modified after that developed by Hogg and Kornberg ('63). The cells were collected by low-speed centrifugation, using a continuous flow attachment to the Servall refrigerated centrifuge, and were washed with Ryley's Ringer-phosphate (Ryley, '52). All operations were carried out at $4^{\circ} \mathrm{C}$. A brei was prepared by passing a $5 \%$ suspension of cells in $0.25 \mathrm{M}$ mannitol (or $0.25 \mathrm{M}$ sucrose) through a sintered glass filter (" $M$ " porosity, Corning Glass Company). Dense $\left(\mathrm{P}_{\mathrm{N}}\right)$ and fluffy $(\mathrm{Pl})$ pellets were obtained after centrifugation at $2,000 \times g$ for ten minutes in a Servall refrigerated centrifuge (Model RC-2, rotor SS-34). Successive pellets were obtained at $18,000 \times g$ for ten minutes (P2) and at $37,000 \times g$ for 30 minutes (P3). The wash from Pl (PIW) and the final supernatant (S) were saved. This schedule is depicted in a diagram (fig. 2).

Analytical methods. The protein content of various cell fractions was determined by Dr. J. F. Hogg (Department of Biochemistry, The University of Michigan) using the biuret procedure of Weichselbaum ('46). Assays of citrate condensing enzyme and succinate dehydrogenase were also performed by Dr. Hogg (see Dixon and Kornberg, '59; Hogg and Kornberg, '63).

Electron microscopy. Samples of the various cell fractions were prepared for electron microscopy by Drs. I. J. Bak and A. M. Elliott (Department of Zoology, The University of Michigan). Pellet material was concentrated at $37,000 \times g$ for 30 minutes in the Servall refrigerated centrifuge and the concentrate was fixed in $1 \%$ osmium fixative buffered with Veronal acetate. The pellets were imbedded 
in Epon 812 and the sections were stained with uranylacetate (see Bak and Elliott, '62).

Preparations of cilia. Three methods were used for preparing cilia, although only one appears satisfactory for variety 1 of $T$. pyriformis. The salt-ethanol method of Preer and Preer ('59) and the verseneethanol-CaCl${ }_{2}$ method of Watson, Hopkins, and Randall ('61) resulted in much cell breakage; thus, the "cilia" fractions were heavily contaminated with other cellular components. The most satisfactory method was one developed by F. M. Child ('59 and personal communication). Washed cells from $500 \mathrm{ml}$ of culture were suspended by gentle stirring in $10 \mathrm{ml}$ of $0.15 \mathrm{M} \mathrm{CaCl}_{2}$ in $0.05 \mathrm{M}$ sodium acetate buffer at $\mathrm{pH} 5.4$. Approximately $30 \mathrm{ml}$ of cold $\left(-7^{\circ}\right) 25 \%$ $(\mathrm{v} / \mathrm{v})$ glycerol was added, and the mixture was stirred vigorously once a minute for 12 minutes with a blunt glass rod. The "bodies" were sedimented at $1,000 \times g$ for ten minutes in the Servall refrigerated centrifuge. The supernatant containing clean cilia was then spun at $12,000 \times g$ for 20 minutes.

Microscopic examination. Preparation of the various types of cell fractions was followed by phase contrast microscopy.

\section{RESULTS}

\section{Electrophoretic resolution of isozymes}

The number of isozymes that can be separated electrophoretically is dependent upon the $\mathrm{pH}$ of the buffers used ( $\mathrm{S}$. L. Allen, '61a; Allen, Hegenaur, and Licht, unpublished). At maximal resolution six isozymes are visible in zymograms of whole cell extracts of both $E-1^{B} / E-1^{B}$ and $E-1^{c} / E-1^{c}$ genotypes, although the $\mathrm{pH}$ at which maximal resolution occurs is slightly different (fig. 1). In an earlier report (S. L. Allen, '61a) a numbering system was adopted. These are the "old" numbers on the diagram. A "new" numbering system will be used in the present discussion. For example, E-1B refers to the E-1B group and B-1, 2, 3, 4, 5, and 6 refer to specific isozymes. These numbers are useful as references. They are tentative, since it is clear that each group contains additional isozymes in purified en-
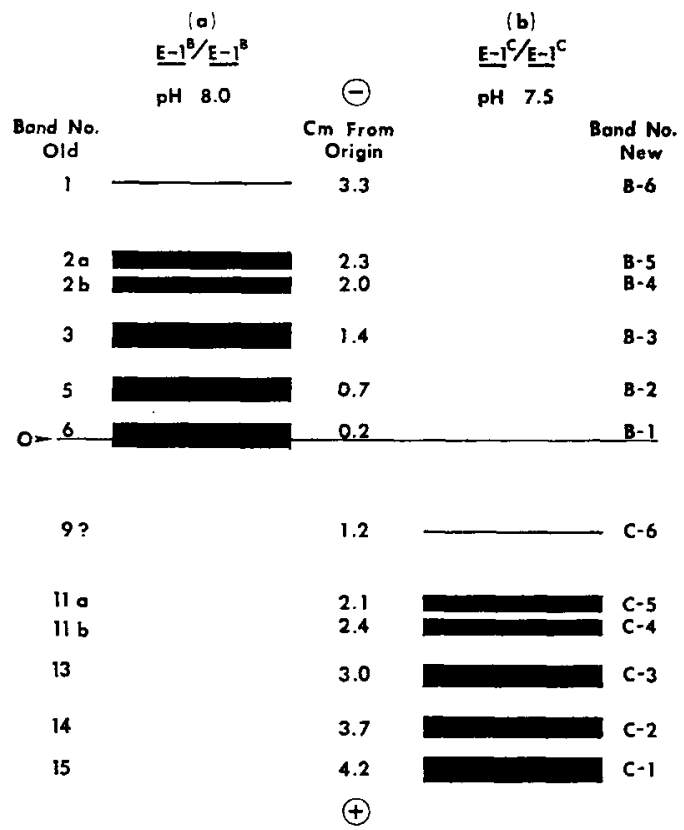

Fig. 1 The E-1 esterases of extracts of (a) $E-1^{B} / E-1^{B}$ cells and of (b) $E-1^{C} / E-1^{C}$ cells. The cathode is at the top, the anode is at the bottom and " $O$ " refers to the origin in this diagram and in the subsequent photographs. On the left appear the old band numbers (S. L. Allen, '61a). On the right appear the new band numbers that identify each isozyme. Distances from the origin are recorded in $\mathrm{cm}$ for each isozyme. Electrophoretic separations were achieved using boric acid-Tris buffers, the end tray buffer being $0.3 \mathrm{M}$ and $\mathrm{pH}$ 7.5. The bed buffer was $30 \mathrm{mM}$ and $\mathrm{pH} 8.0$ for (a) and $\mathrm{pH} 7.5$ for (b). This diagram is based on drawings of the actual gels. Band 12 (old number), often seen in the photographs apposed to $\mathrm{C}-3$, is not an $\mathrm{E}-1$ esterase and does not appear on this diagram; it is found in extracts of all strains of T. pyriformis, variety 1 .

zyme preparations (Allen, Hegenaur, and Licht, unpublished).

\section{Separation of isozymes by differ- ential centrifugation}

In attempting to separate distinct types of cell fractions of $T$. pyriformis by differential centrifugation, several steps in the procedure were varied: the manner in which the cells were broken; the suspending medium; and the $g$ forces used in separating the fractions. Even though a satisfactory schedule was finally adopted, it should be noted that the fractions contained a population of cellular components, that the average size of these com- 
ponents decreased in fractions obtained by increasing centrifugal forces, but that most fractions contained more than one type of component, although statistically more of one type than another.

In breaking the cells the sintered giass filter resulted in less damage to cellular components than other methods, i.e., homogenization or forcing cells through a hypodermic needle. Some difficulty, however, was encountered in using the sintered glass filter for bulk preparations or for very concentrated suspensions of cells. In this case a stainless steel filter (Mesh size $20 \mu$; Will Corporation, grade F) was an effective substitute. When neither of these is available, a French pressure cell may be used, although less effectively.

The ease with which cells break varied between different strains. Several C stocks were used, and all were considerably more fragile than the A or B strain cultures. $C$-strain breis were more viscous than the A or B strain breis, especially in higher concentrations of sucrose (or mannitol). This led to a technical problem: separation of distinct types of $\mathrm{C}$ strain cell fractions was much more difficult. This difference in viscosity and in the ease with which distinct fractions could be separated was reflected in a difference between the strains in protein distribution among the cell fractions. If the amount of protein in the filtrate is taken as $100 \%$, the per cent protein found in P2, P3 and S was around $40 \%$ in the $A$ and $B$ strains. This percentage was consistently lower $(30 \%)$ in the same fractions prepared from the $\mathrm{C}$ strain.

With the schedule of differential centrifugation outlined in figure 2 , the mito-

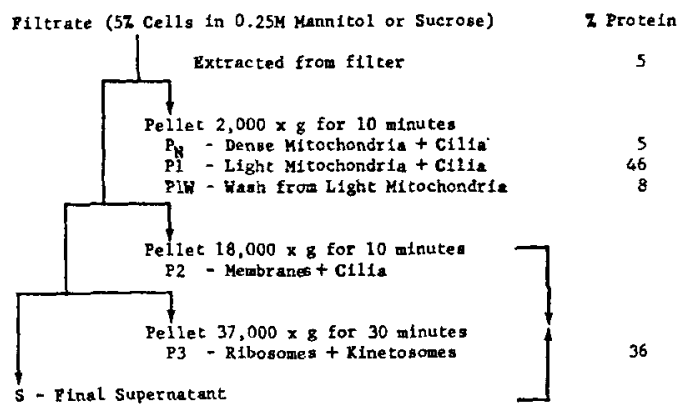

Fig. 2 Schedule of cell fractionation.

chondria were removed in $\mathrm{P}_{\mathrm{N}}$ and $\mathrm{P} 1$. P2 consisted of membranes and cilia, and P3 consisted of small granules. This distribution of cellular components was confirmed by biochemical and morphological identification.

The mitochondrial enzymes, citrate condensing enzyme and succinate dehydrogenase, were largely restricted to $P_{N}$ and P1 (table 1). Over $80 \%$ of citrate condensing enzyme was found in these fractions. Over $90 \%$ of succinate dehydrogenase was found in these fractions derived from the A strain, while $74 \%$ was found in $\mathrm{C}$ strain fractions. The lower value obtained with $\mathrm{C}$ strain material may reflect a strain difference, or it may result from the poor separation achieved with this material.

Electron microscopy was also used to identify the cellular components of these fractions (fig. 3). Mitochondria were predominant in $P_{N}$ and $P 1$, although membranes and cilia were also found in these fractions. P2 contained membranes of assorted sizes, cilia and pieces of cilia. Small granules occurred in P3. Some may be ribosomes, and others may be kinetosomes.

TABLE 1

Distribution of citrate condensing enzyme or succinate dehydrogenase in cell fractions ${ }^{1}$

\begin{tabular}{|c|c|c|c|c|c|c|}
\hline & \multirow{2}{*}{\multicolumn{2}{|c|}{$\frac{\text { Citrate condensing enzyme }}{\text { B Strain }}$}} & \multicolumn{4}{|c|}{ Succinate dehydrogenase } \\
\hline & & & \multicolumn{2}{|c|}{ A Strain } & \multicolumn{2}{|c|}{ C Strain } \\
\hline & $\begin{array}{l}\text { Specific } \\
\text { activity } \\
\mu \mathrm{M} / \mathrm{mgP} / \mathrm{Hr}\end{array}$ & $\begin{array}{c}\% \\
\text { Relative } \\
\text { distribution }\end{array}$ & $\begin{array}{l}\text { Specific } \\
\text { activity } \\
\mu \mathrm{M} / \mathbf{m g P} / \mathbf{H r}\end{array}$ & $\begin{array}{c}\% \\
\text { Relative } \\
\text { distribution }\end{array}$ & $\begin{array}{c}\text { Specific } \\
\text { activity } \\
\mu \mathrm{M} / \mathbf{m g} \mathrm{P} / \mathrm{Hr}\end{array}$ & $\begin{array}{c}\% \\
\text { Relative } \\
\text { distribution }\end{array}$ \\
\hline $\mathbf{P}_{\mathrm{N}}$ & 7.7 & 34.1 & 2.3 & 20.5 & $<0.2$ & 12 \\
\hline P1 & 1.0 & 48.2 & 2.4 & 71.8 & 3.5 & 62 \\
\hline S1 & 0.5 & 18.7 & 0.2 & 7.7 & $<0.2$ & 26 \\
\hline
\end{tabular}

1 These assays were performed by Dr. James F. Hogg, Department of Biochemistry, The University of Michigan. 
The esterase isozymes of these cell fractions were analyzed by starch gel electrophoresis. Isozymes $1,2,3,4,5$, and 6 were usually present in the whole cell extracts of these strains (fig. 4), but occasionally only isozymes $1,2,3$, and 4 were present (fig. 5). The discordancy in the number of isozymes present in the starting material apparently resides in differences in composition of the media used (see below). In the illustrated experiments, the $A$ and $C$ strain cultures were grown in $1 \%$ proteose peptone (fig. 4), while the B strain culture was grown in a higher concentration of peptone (fig. 5). With the schedule of differential centrifugation outlined in figure 2 one of the isozymes was enriched in small particles (P2 and P3). A second isozyme seemed to be associated with $\mathrm{P} 2$, and the other isozymes sedimented in the lowest speed fractions ( $P_{\mathrm{N}}$ and $\left.\mathrm{P} 1\right)$. The final supernatant and the wash from P1 were largely devoid of esterase activity (fig. 5). The principal isozyme associated with small particles was B-3 or C-3. Since the $A$ and $B$ strain fractions were more cleanly separated than the $\mathrm{C}$ strain fractions, the distinctness of the separation of $\mathrm{B}-3$ in small particles is much more striking than that of C-3. B-5, when present (fig. 4, A strain), sedimented less rapidly than B-4. It may be associated with intermediate sized particles.

This pattern of distribution was observed repeatedly using other schedules of differential centrifugation. When homogenates were prepared in buffered saline and the schedule of Preer and Preer ('59) was followed, B-3 and C-3 were enriched in pellets sedimented at $25,000 \times g$ for two minutes. This fraction is their microsomal fraction. When $0.88 \mathrm{M}$ sucrose was used as the suspending medium, B-3 and C-3 were not enriched in pellets sedimented at 18,000 $\times g$ for ten minutes, but they were enriched in pellets sedimented at $37,000 \times g$ for 30 minutes. Pellets obtained after centrifugation at $105,000 \times g$ for 60 minutes (in a Spinco preparative ultracentrifuge, Model $\mathrm{L}$, rotor no. 40) were largely devoid of esterase activity.

These experiments suggest that a partial separation of the esterase isozymes has been achieved. One of the isozymes (B-3 or C-3) appears to be associated with cellu- lar components of small size. These may be small pieces of membranes, cilia, ribosomes, or kinetosomes. Decision as to which of these components is involved is not easy, but supporting evidence from other types of experiments suggests that the microsomes (membranes with attached ribosomes) may be the source of this isozyme.

\section{Lack of Association of esterases and cilia}

The possible association of one of the esterase isozymes (B-3 or C-3) with cilia was reported previously (S. L. Allen, '61a). These preparations of cilia were made according to the salt-ethanol method of Preer and Preer ('59). Living cells were suspended in $\mathrm{NaCl}$-ethanol, buffered to $\mathrm{pH}$ 7.0 , and were mechanically agitated by repeated pipetting, thereby causing the cilia to break at their point of entry in the pellicle. The "bodies" were removed by lowspeed centrifugation, and the "cilia" were sedimented from the supernatant by centrifugation at $25,000 \times g$ for two minutes Intensive study of this procedure made it clear that it was not the cilia but other contaminating components in this fraction that were responsible for the enhancement of B-3 and C-3. Evidently Tetrahymena is far more fragile than Paramecium; even gentle stirring in the salt-ethanol mixture will effect considerable disruption of the cells. Several experiments were performed in which the amount of mechanical agitation was varied. A correlation was observed between the degree of disruption and the degree of enhancement of B-3 or $\mathrm{C}-3$ in the high-speed pellets. Washing experiments confirmed this observation. With successive washings of the low-speed fraction, a progressive loss of $\mathrm{B}-3$ or $\mathrm{C}-3$ was observed accompanied by an increase of $\mathrm{B}-3$ or $\mathrm{C}-3$ in the high-speed fraction.

Other methods for preparing cilia were sought. The technique of Watson, Hopkins, and Randall ('61) was also unsatisfactory because of cell disruption. The glycerol procedure of Child ('59 and personal communication) was satisfactory, and preparations of cilia could be obtained that were free of other cellular components. When such cilia preparations were examined electrophoretically, they were 
devoid of esterase activity; therefore, the source of B-3 or C-3 cannot be the cilia.

\section{Changes in activity of isozymes during the growth cycle}

Variations in isozymic activity of cells in different stages of the growth cycle were observed some time ago (S. L. Allen, '60). B-3 was found to be intensely active in logarithmic cells. In stationary cells it decreased in activity relative to the other isozymes and B-2 increased in activity. No apparent homologies seemed to exist in the behavior of isozymes between the E-1B and $\mathrm{E}-1 \mathrm{C}$ groups. At this time the electrophoretic resolution of the E-1C isozymes was poor. Since then, conditions for the maximal resolution of the isozymes of each group have been found to be slightly different. This being the case, a repetition of the growth cycle experiments seemed in order. This study was extended to include the effects of enriched media and of other types of media on the pattern of isozymic activities.

In the first series of experiments $1 \%$ proteose-peptone was employed as the growth medium. Samples of cells were taken from cultures grown for $0.5,1,2,3$, $4,5,7$, and 10 days at $30^{\circ} \mathrm{C}$ and extracts of equivalent cell concentration were prepared. Although the total enzymatic activity may rise slightly in older cells, the distribution of activity among the isozymes was different in cells of different age. Each isozyme of a group showed a sequence of activities that progressed during the growth cycle, and similar isozymes in different groups (B-3 and C-3) showed similar behavior (fig. 6). Isozymes 3,5 and 6 were very active in logarithmic cells, Isozymes 2 and 4 were very active in stationary cells, and Isozyme 1 changed little with age, possibly being more active in logarithmic cells. The actual time schedule varied with the stock, but the pattern of change was similar in different stocks of the same strain and in different strains. These experiments suggested that the isozymes could be divided into two subgroups, regardless of genotype. Isozymes $1,3,5$, and 6 form one group (logarithmic isozymes) and Isozymes 2 and 4 form the other group (stationary isozymes). These differences seemed to reflect real differ- ences in the metabolism of the cell. The influence of extracts of cells that were different metabolically was tested in mixing experiments. Intra-strain and interstrain mixtures of logarithmic and stationary extracts were prepared in all combinations. Each mixture was the sum of the individual extracts, and no influence of one extract upon another was evident. Thus, the differences in activity between isozymes of logarithmic and stationary cells seem to be stable.

Attention was next focussed on ways of extending the logarithmic phase of the growth cycle in time so that a more detailed analysis of this phase might be possible. This was accomplished by using enriched media. When cultures were grown for one day in $1 \%, 2 \%$ or $4 \%$ proteosepeptone, a depression of Isozymes 5 and 6 was observed in the higher concentrations of peptone (fig. 7a); whereas, the activities of Isozymes 3 and 1 were similar in these cultures. When cultures were grown for a varying number of hours or days in higher concentrations of peptone or in skimmed milk, a temporal sequence in the appearance of each isozyme was observed (fig. $7 \mathrm{~b}, \mathrm{c}$ ). In peptone Isozymes 3 and 1 appeared first, then 5 and 6 , and finally 2 and 4 . In some skimmed milk cultures harvested earlier than five days, Isozyme 3 was predominant, with only trace activities of other isozymes. Some variation occurred in the temporal sequence of Isozymes 4 and 5. Usually Isozyme 5 appeared earlier than 4 in peptone (figs. $6,7 \mathrm{a}, \mathrm{b}$ ) but the order may be reversed both in peptone (fig. 4) and in skimmed milk (fig. $7 \mathrm{c}$ ). The peak activity of Isozyme 5 was, however, at an earlier stage than that of Isozyme 4 , the latter being very active in stationary cells. This observation emphasizes the point that two aspects of isozymic activity can be studied by using enriched media and by varying the amount of growth: the time of first appearance of an isozyme during logarithmic growth; and the time of peak activity of an isozyme during the growth cycle. Analysis of first appearance was facilitated by the use of enriched media that effectively extended the logarithmic phase of the growth cycle. Presumably, the longer this period is extended, the finer will be the resolution of 
the temporal relationships of the isozymes. First appearance and peak activity were frequently correlated for a particular isozyme. This was usually the case for Isozymes 2 and 4: they appeared last and they reached peak activities last. However, Isozyme 4 could appear early. In the higher concentrations of peptone Isozymes 2 and 4 never seem to reach the levels of activity observed in $1 \%$ peptone, and the level of activity of Isozyme 3 did not decrease in the older samples (compare figs. $7 \mathrm{~b}$ and 6 ).

The isozymic pattern reflected the metabolic state of the cell. Thus, other growth media were used in order to ascertain if gross compositional differences resulted in variations in isozymic pattern. Cells grown in synthetic medium or bacterized medium had the same array of isozymes as those grown in peptone. The same sequence of change in pattern was observed, although it was somewhat delayed in time. These observations suggest that gross differences in the activities of the isozymes do not arise as a result of wide variations in the composition of the medum. Of more importance is the influence of the medium on the stage of growth of the cells, and changes in activity of the isozymes occur as the cells age. These changes appear to follow a certain sequence during the course of the growth cycle, although minor variations in sequence may occur in different media. In rich media the logarithmic phase is extended so that these changes are delayed. The sequence of change appears to be similar in different $E-1$ genotypes.

\section{DISCUSSION}

A partial separation of the esterase isozymes has been achieved by differential centrifugation. In each genotype one isozyme appears to be localized to the microsomes, another may be present in somewhat larger particles, while the remaining isozymes appear in fractions that sediment rapidly and contain predominantly mitochondria. Similar intracellular distributions are observed in the two genotypes. Although most experiments were made on cells in the stationary phase of the growth cycle, a few experiments employed cells that were in logarithmic growth. Such fractions showed a distribution of isozymes similar to that observed for stationary cells. These intracellular distributions indicate a compartmentalization of the enzyme.

While the significance of such compartmentalization is largely unknown, multiple forms of an enzyme may be distributed in different parts of the cell. J. M. Allen ('61a) localized a lactate dehydrogenase (LDH) in the apex of certain cells in mouse epididymis. This LDH may be similar to the LDH-X of Blanco and Zinkham ('63) Zinkham, Blanco, and Kupchyk, ('63) and Goldberg ('63). Vesell and Bearn ('62) found that LDH-5 could be enriched in a nuclear fraction prepared from duck erythrocytes; the other LDH's remained in the supernatant. Two electrophoretically distinct malate dehydrogenases can be separated by differential centrifugation $(J$. M. Allen, '61b). Two sites of localization of beta-glucuronidase are implied by the studies of Paigen ('61) in the mouse. In this case an interesting genetic influence on the attachment of the enzyme to these sites was suggested. In strain DBA/2 an enzyme of similar properties was present in both lysosomes and microsomes, while in $\mathrm{C} 3 \mathrm{H} / \mathrm{Ha}$ a less stable enzyme was found only in the lysosomes. Paigen concluded that mutations in the structure of the enzyme resulted in changes in the morphology of these cellular components.

Often significant differences in function can be assigned to the various molecular forms of an enzyme. LDH is a classic example, where responses to oxygen tension alter a cell's repertoire (Markert, '63; Dawson, Goodfriend, and Kaplan, '64). Unfortunately, the function of the esterase isozymes is not understood; even the natural substrate of the enzyme is unknown. Attempts to classify this esterase according to conventional schemes have not been satisfactory, although at the moment it is suspected of being an aliesterase (Allen, Hegenaur, and Licht, unpublished). These esterases are probably not associated with food vacuoles and lysosomes, since they were similar in cells grown in media that differ in provoking vacuole formation (see Seaman, '61; Allen, Misch, and Morrison, '63a). 
Striking variations in the first appearance and in the activities of the isozymes are observed in cells at different stages in the growth cycle. All isozymes appear in logarithmic cells, but they appear in a certain sequence. Isozyme 3 , which is found in the microsomal fraction, appears first, sometimes with Isozyme 1. Certain isozymes have peak activities in logarithmic cells (Isozymes 3,5 and 6 ), and others have peak activities in stationary cells (Isozymes 2 and 4 ). Since homologous behavior is observed in different genotypes, that portion of the enzyme molecule which is sensitive to factors associated with the growth cycle must be similar in the two genotypes. It follows that differences in individual isozymes must somehow be secondarily acquired.

The isozymes appear to be under single gene control (S. L. Allen, '61a), and each group of isozymes is homologous in intracellular distribution and in behavior during the growth cycle. In heterozygotes both groups of isozymes are present. B-3 and $\mathrm{C}-3$ are found in the microsomes obtained by differential centrifugation, and they are also the most active isozymes in logarithmic cells. The other isozymes in these groups also undergo the sequence of changes observed during the growth cycle that was found in homozygotes. So far, there is no genetic evidence for additional genes influencing these esterases, but they would not be detected if mutations of such genes are not present in the available stocks of Tetrahymena.

Assuming single gene control, the primary gene product must in some manner be changed. Mutations thus far observed in the E-1 gene do not affect the active site of the enzyme, since enzymatic activity is comparable in the two genotypes. Nor do they affect the associations that the primary gene product makes in elaborating the isozymes, because the isozymes in different groups are homologous. The primary gene product may form associations with several types of molecules: for example, with another protein, as in the case of the LDH's (Markert, '61; Cahn et al., '62); or with a polysaccharide, as in the case of the human transferrins (Parker and Bearn, '62). The nature of the associations that are pertinent to the esterase iso- zymes is not known. It is possible that the isozyme found in the microsomal fraction and which appears early in logarithmic growth may represent the newly synthesized form of the enzyme and be closest in structure to the primary gene product. The other isozymes could arise by modification of this molecular form. Addition or loss of charged groups would result in the formation of macromolecules that differ in net charge. Experimental manipulation of these isozymes has been successfully carried out (Allen, Hegenaur, and Licht, unpublished). New forms differing in mobility from the native forms can be generated, and, as they are generated, the native forms disappear.

If changes in molecular form normally occur during the genesis of these isozymes, the manner in which these changes occur in the cell is not known, nor is the relationship to structure understood. Presumably certain configurations and certain attachments to structure are favored at the expense of others under a given environmental condition. The repeatability of the isozymic pattern and its response to a changing cellular environment suggest that the changes are not random, whatever their nature.

\section{ACKNOWLEDGMENTS}

I would like to acknowledge the assistance of Mr. Keith A. Arnold, Mrs. Barbara Morrison Licht, and Mr. John C. Hegenaur.

\section{SUMMARY AND CONCLUSIONS}

The esterase isozymes of variety 1 of $T$. pyriformis can be separated by electrophoresis is starch gels. At maximal resolution there are two groups of six isozymes and these groups are under the control of alleles at the E-1 locus. In this study cell fractions were prepared by differential centrifugation. In each genotype one isozyme (Isozyme 3 ) appears to be localized to the microsomes, another may be present in somewhat larger particles, while the remaining isozymes appear in fractions that sediment with low centrifugal forces. Intensive analysis of the isozymes in cells of different age and in cells grown in enriched media suggests that each isozyme has a characteristic time of appearance during logarithmic growth and a character- 
istic time of peak activity during the growth cycle. Certain isozymes have peak activities during the logarithmic phase and others have peak activities during the stationary phase. Homologous behavior is observed in different genotypes. Since Isozyme 3 is the first to appear during logarithmic growth and is present in microsomes, the molecular form of Isozyme 3 may be close to that of the newly synthesized enzyme. The other isozymes may be derived from this form during their incorporation into cellular structures.

\section{LITERATURE CITED}

Allen, J. M. 1961a Multiple forms of lactic dehydrogenase in tissues of the mouse: their specificity, cellular localization, and response to altered physiological conditions. Ann. N. Y. Acad. Sci., 94: 937-951.

1961b The distribution of members of multiple molecular series of enzymes in subcellular structures. Abstracts Am. Soc. Cell Biology: 7.

Allen, S. L. 1960 Inherited variations in the esterases of Tetrahymena. Genetics, 45: 10511070.

1961a Genetic control of the esterases in the protozoan Tetrahymena pyriformis. Ann. N. Y. Acad. Sci., 94: 753-773.

$1961 \mathrm{~b}$ The role of the esterase isozymes in Tetrahymena. Am. Zool., 1: 338.

1964 Linkage studies in variety 1 of Tetrahymena pyriformis : a first case of linkage in the ciliated protozoa. Genetics, 49: 617-627.

Allen, S. L., J. C. Hegenaur and B. M. Licht, unpublished.

Allen, S. L., M. S. Misch and B. M. Morrison 1963a Variations in the electrophoretically separated acid phosphatases of Tetrahymena. J. Histochem. Cytochem., 11: 706-719.

J. Histo $1963 \mathrm{~b}$ Genetic control of an acid phosphatase in Tetrahymena: formation of a hybrid enzyme. Genetics, 48: 1635-1658.

Bach, M. L., E. R. Signer, C. Levinthal and I. W. Sizer 1961 The electrophoretic patterns of alkaline phoshpatase from various $E$. coli $\mathrm{mu}$ tants. Feder. Proc., 20: 255.

Bak, I. J., and A. M. Elliott 1962 Structural changes in the mitochondria of Tetrahymena pyriformis during the growth cycle. Proc. 5th Internatl. Congr. Electron Microscopy, UU-13.

Blanco, A., and W. H. Zinkham 1963 Lactate dehydrogenase in human testes. Science, 139: 601-602.

Cahn, R. D., N. O. Kaplan, L. Levene and E. Zwilling 1962 Nature and development of lactic dehydrogenases. Science, 136: 962-969.

Child, F. M. 1959 The characterization of the cilia of Tetrahymena pyriformis. Exptl. Cell Research, 18: 258-267.
Personal communication.

Dawson, D. M., T. L. Goodfriend and N. O. Kaplan 1964 Lactic dehydrogenases: functions of the two types. Science, 143: 929-933.

Dixon, G. H., and H. L. Kornberg 1959 Assay methods for key enzymes of the glyoxylate cycle. Biochem. J., 72: 3P.

Elliott, A. M., L. E. Brownell and J. A. Gross 1954 The use of Tetrahymena to evaluate the effect of gamma radiation on essential nutrilites. J. Protozool., 1: 193-199.

Goldberg, E. 1963 Lactic and malic dehydrogenases in human spermatozoa. Science, 139: 602-603.

Hogg, J. F., and H. L. Kornberg 1963 The metabolism of $\mathrm{C}_{2}$-compounds in micro-organisms. 9. Role of the glyoxylate cycle in protozoal glyconeogenesis. Biochem. J., 86: $462-$ 468.

Levinthal, C., E. R. Signer and K. Fetherolf 1962 Reactivation and hydridization of reduced alkaline phosphatase. Proc. Natl. Acad Sci. U. S., 48: 1230-1237.

Markert, C. L. 1961 Isozymes in kidney development. In: Heredity, Developmental and Immunologic Aspects of Kidney Disease. Proc. 13th Ann. Conf. Kidney, Edited by J. Metcoff. Northwestern Univ. Press, Evanston, Ill., pp. 54-64.

1963 Epigenetic control of specific protein synthesis in differentiating cells. In: Cytodifferentiation and Macromolecular Synthesis, Edited by M. Locke, Academic Press, New York, N. Y., pp. 65-84.

Markert, C. L., and F. Møller 1959 Multiple forms of enzymes: tissue, ontogenetic, and species specific paiterns. Proc. Natl. Acad. Sci. U. S., 45: 753-763.

Nanney, D. L. 1959 Genetic factors affecting mating type frequencies in varitety 1 of Tetrahymena pyriformis. Genetics, 44: 1173-1184.

Paigen, K. 1961 The effect of mutation on the intracellular location of $\beta$-glucuronidase. Exptl. Cell Research, 25: 286-301.

Parker, W. C., and A. G. Bearn 1962 Studies on the transferrins of adult serum, cord serum, and cerebrospinal fluid. The effect of neuraminidase. J. Exptl. Med., 115: 83-105.

Preer, J. R., and L. B. Preer 1959 Gel diffusion studies on the antigens of isolated cellular components of Paramecium. J. Protozool., 6: 88-100.

Ryley, J. F. 1952 Studies on the metabolism of the protozoa. 3. Metabolism of the ciliate Tetrahymena pyriformis (Glaucoma pyriformis). Bjochem. J., 52: 483-492.

Seaman, G. R. 1961 Some aspects of phagotropy in Tetrahymena. J. Protozool., 8: 204212.

Vesell, E. S., and A. G. Bearn 1962 Localization of a lactic dehydrogenase isozyme in nuclei of young cells in the erythrocyte series. Proc. Soc. Exptl. Biol. and Med., 111: 100104. 
Watson, M. R., J. M. Hopkins and J. T. Randall 1961 Isolated cilia from Tetrahymena pyriformis. Exptl. Cell Research, 23: 629-631.

Weichselbaum, T. E. 1946 An accurate and rapid method for the determination of proteins in small amounts of blood serum and plasma. Amer. J. Clin. Pathol. Techn. Sect., 10: 40-49.
Wróblewski, F. (Editor) 1961 Multiple Molecular Forms of Enzymes. Annals N. Y. Acad. Sci., 94, Art. 3: 657-1030.

Zinkham, W. H., A. Blanco and L. Kupchyk 1963 Lactate dehydrogenase in testis: dissociation and recombination of subunits. Science, 142: 1303-1304. 
PLATES 


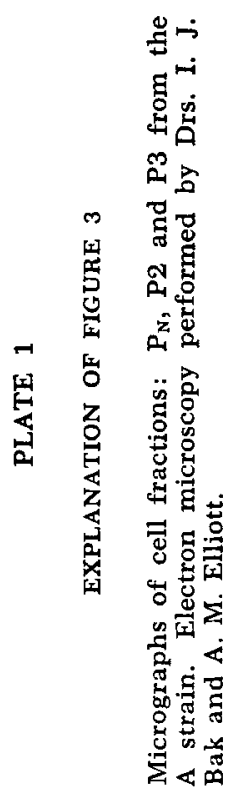



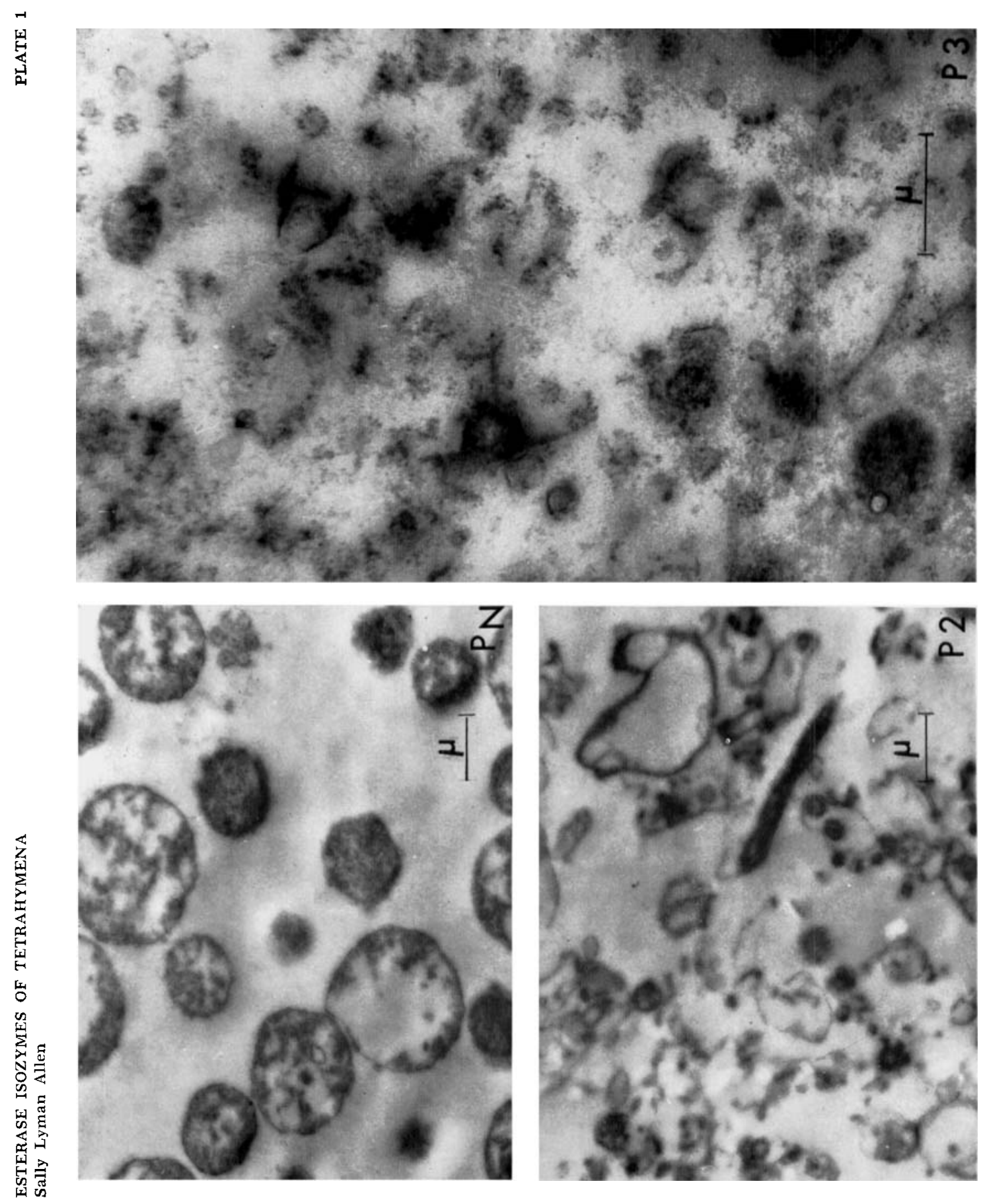


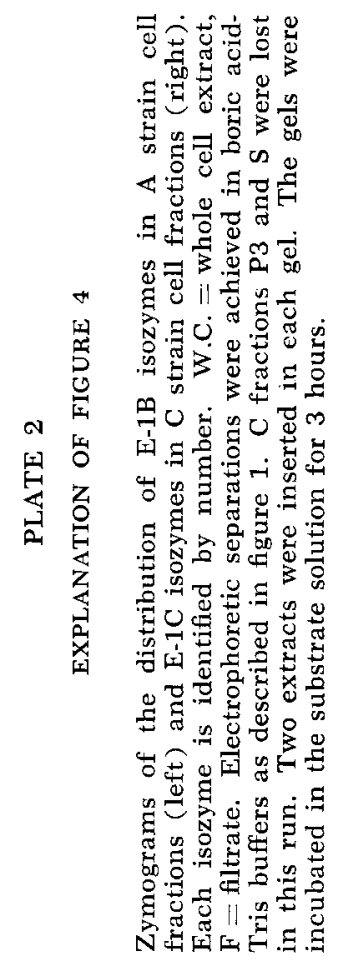


㠃

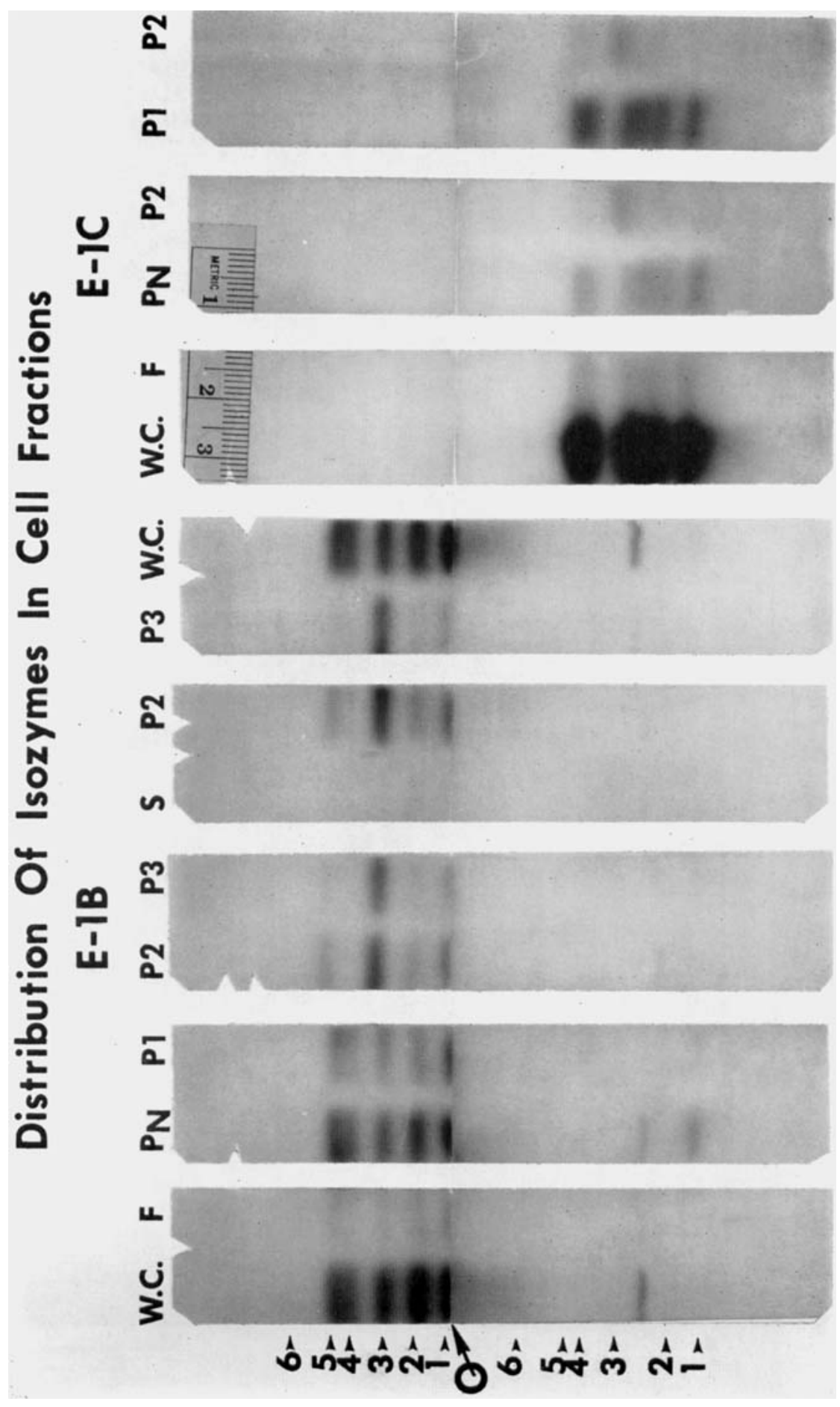




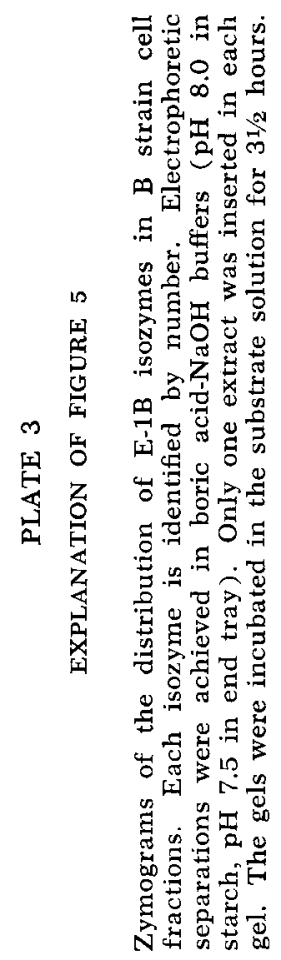


占
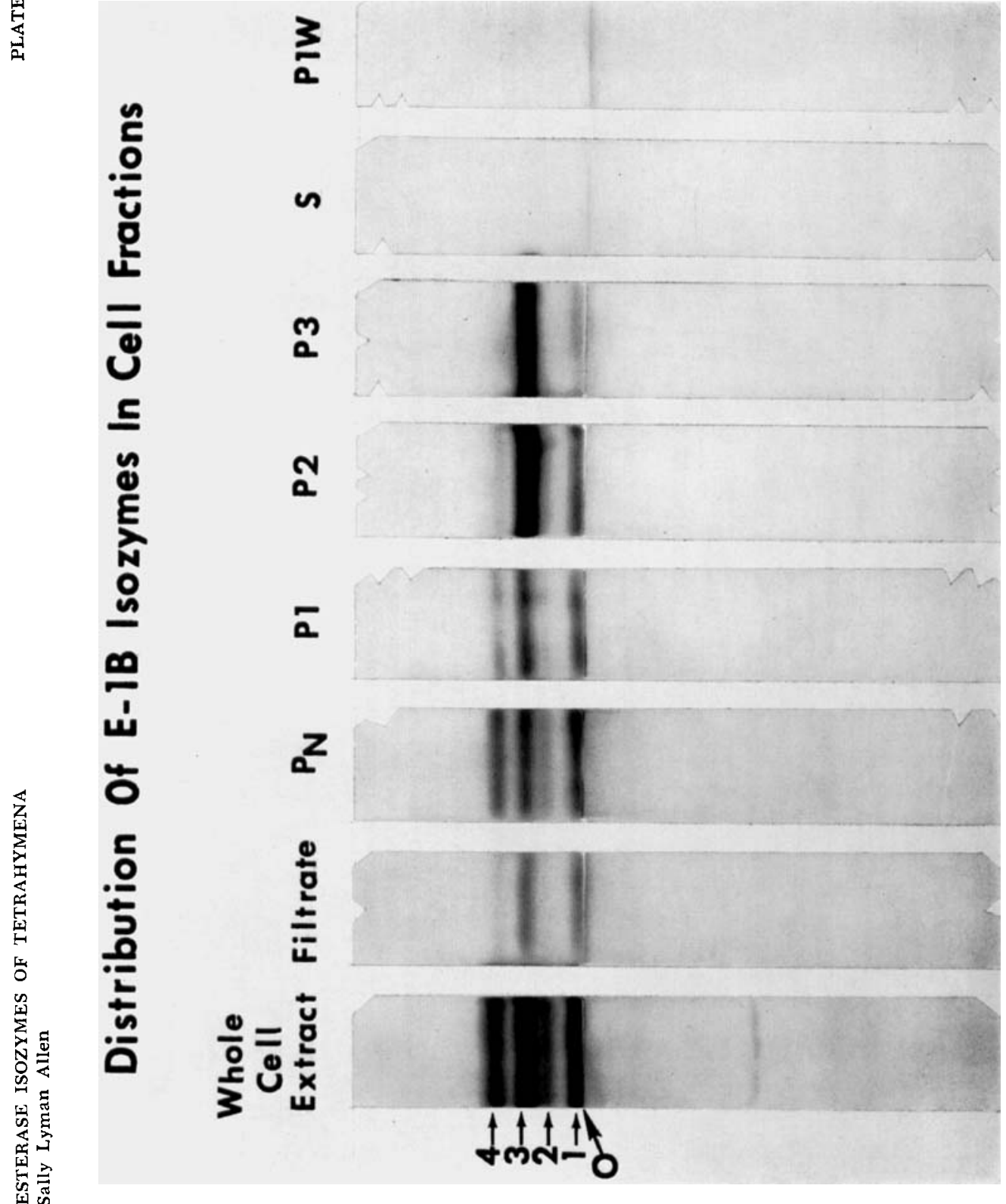


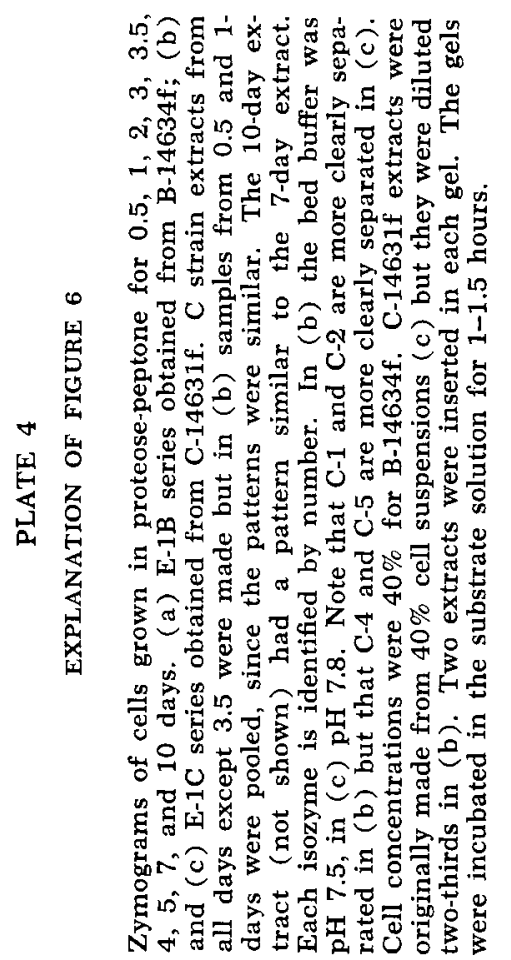


䆞
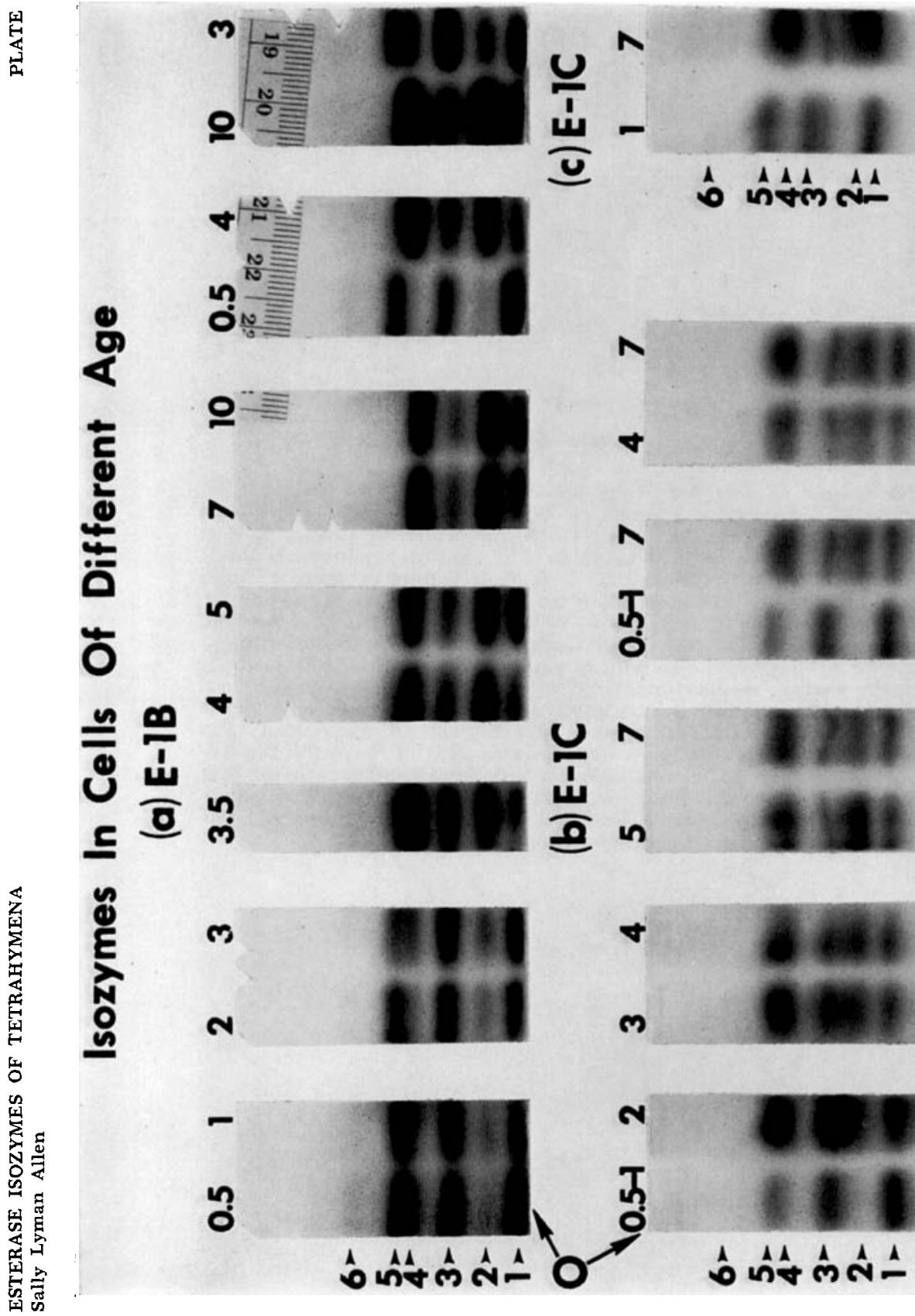
PLATE 5

EXPLANATION OF FIGURE 7

Zymograms of $E-1^{B} / E-1^{B}$ cells grown in enriched media. (a) Extracts of 1-day cultures grown in $1 \%, 2 \%$ or $4 \%$ proteose-peptone. (b) Extracts of cells grown for 4 or 8 (h) hours, or 1, 2, 3, 4, 5, 6, 7 , or 9 (d) days in $4 \%$ (top) or $2 \%$ (bottom) proteose-peptone. (c) Extracts of cells grown for 5, 6, 7, or 9 days in skimmed milk medium. In (a) and (b) cells were grown in $100 \mathrm{ml}$ of medium in $250 \mathrm{ml}$ Erlenmeyer flasks; in (c) cells were grown in $1 \mathrm{~L}$ of medium in $3 \mathrm{~L}$ Erlenmeyer flasks. Cell concentrations were $35-40 \%$ in (a) and (b). Volumetric estimates of plateau cell populations were made in the various media. Compared to $1 \%$ peptone, these populations were roughly $2 \times$ in $2 \%, 3 \times$ in $4 \%$ and $6 \times$ in skimmed milk. Each isozyme is identified by number. Electrophoretic separations were achieved in boric acid-Tris buffers as described in figure 1. Two extracts were inserted in each gel. The gels were incubated in the substrate solution for 2-3 hours $(a, b)$ or one-half hour (c). Zymograms of $E-1^{C} / E-1^{c}$ cells grown in enriched media were also prepared. The results were comparable to those shown above. 


\section{Isozymes In Cells Grown In Enriched Media}

(a)

(c)

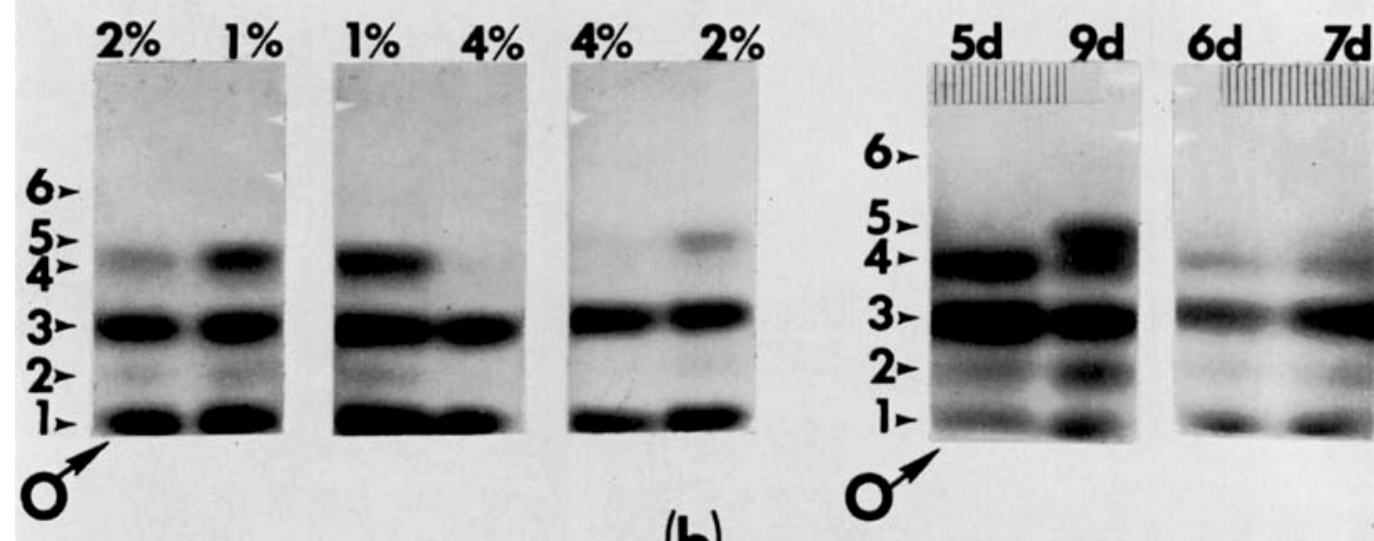

(b)

4h $8 \mathrm{~h}$ Id $2 d \quad 3 d \underset{4 \%}{4 d} 5 d \quad$ 6d $7 d \quad 9 d$

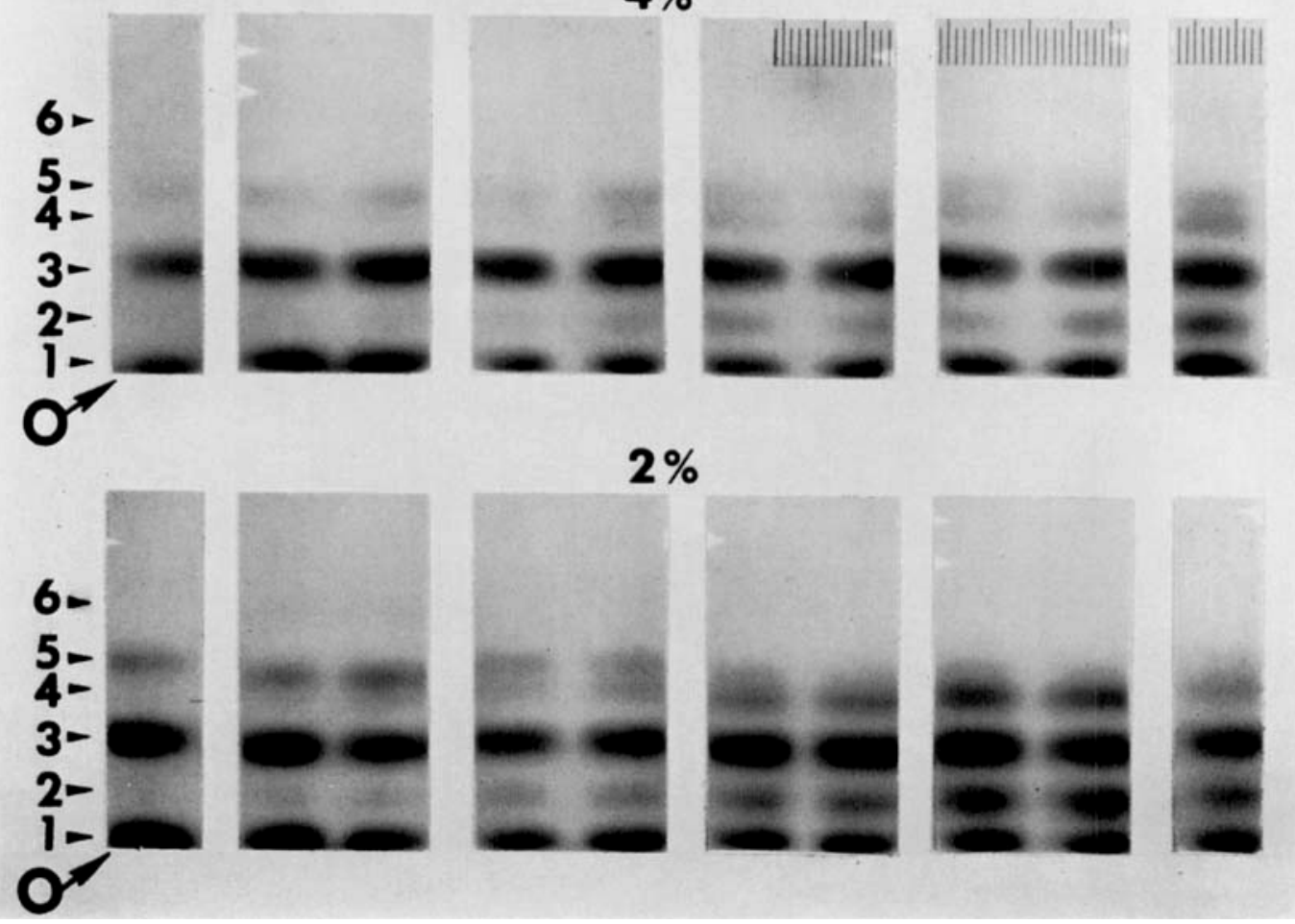

